Revista Thema

\begin{tabular}{l|l|l} 
V.20 & Especial & 2021
\end{tabular} p.328-341
DOI: http://dx.doi.org/10.15536/thema.V20.Especial.2021.328-341.2165

ISSN: $2177-2894$ (online)

\title{
As redes sociais como promotoras de extensão
} universitária: em campanha contra a COVID-19

Social networks as promoters of university extension: in a campaign against COVID-19

Aline Joana Rolina Wohlmuth Alves dos Santos ${ }^{1}$, Leandro Lampe ${ }^{2}$, Vitória Schiavon da Silva ${ }^{3}$, Letícia Leal Moreira ${ }^{4}$, Eduarda Vieira de Souza ${ }^{5}$, Suzana Rosa de Souza ${ }^{6}$

\section{RESUMO}

Em tempos de distanciamento social, medida fundamental para o enfrentamento da pandemia causada pelo novo coronavírus, adaptações foram necessárias em diversos âmbitos, inclusive no acadêmico. Em face desse momento sem precedentes, o Projeto Transfere colaboradores, que atuam em ações de extensão universitária na Universidade Federal de Pelotas, passaram a exercer atividades por meio das redes sociais. Assim, o objetivo deste estudo foi evidenciar a possibilidade de uso das redes sociais para promover extensão universitária, em meio à pandemia, utilizando Facebook e Instagram para divulgar informações e instruções cotidianas relacionadas à COVID-19, além de avaliar a repercussão das informações divulgadas nas comunidades online, por meio de curtidas, compartilhamentos e envolvimentos alcançados por cada post. A análise dos perfis @projetotransferenessas redes apontaram um alcance de mais de 30 mil pessoas, durante os meses de abril a agosto de 2020, com 12 postagens distribuídas semanalmente, evidenciando o amplo alcance de instruções, recomendações e esclarecimentos sobre o tema às comunidades online.

Palavras-chave: Coronavírus; isolamento; comunidades; Facebook; Instagram.

\section{ABSTRACT}

Social distancing is a fundamental measure for facing the pandemic caused by the new coronavirus. Adaptations were necessary for several areas, including the academic one. Due to this unprecedented moment, the Transfere Project and collaborators, which promote university extension actions at the Federal University of Pelotas, started to offer activities through social networks. Thus, this paper aims to highlight

\footnotetext{
${ }^{1}$ Professora Associada I no Centro de Ciências Químicas, Farmacêuticas e de Alimentos (CCQFA), Universidade Federal de Pelotas - UFPel, Pelotas/RS - Brasil. E-mail: alinejoana@gmail.com

${ }^{2}$ Mestrando em Educação Profissional e Tecnológica, Universidade Federal de Santa Maria - UFSM, Santa Maria/RS Brasil. E-mail: leandroolampe@gmail.com

${ }^{3}$ Mestranda em Química, Universidade Federal de Pelotas - UFPel, Pelotas/RS - Brasil. E-mail: vitoriaschiavondasilva@ gmail.com

${ }^{4}$ Graduanda em Licenciatura em Química, Universidade Federal de Pelotas - UFPel, Pelotas/RS - Brasil. E-mail: lealmleticia@gmail.com

${ }^{5}$ Idem. E-mail: eduardavdes99@hotmail.com

${ }^{6}$ Idem. E-mail: suzana.rds.1996@gmail.com
} 


\section{Revista Thema}

v.20

Especial 2021

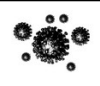

Edição Especial COVID-19

the possibility of using social networks to promote university extension during the pandemic time. Facebook and Instagram were used to disseminate information and provide daily instructions related to COVID-19. The repercussion was assessed through likes, shares, and engagements achieved by each post. The analysis of @projetotransfereprofiles in these social networks indicated a reach of more than 30 thousand people, between April to August 2020, with 12 posts distributed weekly, that provided a wide range of instructions, recommendations, and clarifications on the subject to online communities.

Keywords: Coronavirus; isolation; communities; Facebook; Instagram.

\section{INTRODUÇÃO}

O isolamento social e fechamento de escolas públicas foram medidas adotadas para conter a disseminação do novo coronavírus (Sars-Cov-2). No Brasil, a principal política pública de enfrentamento da doença foi o isolamento social, em alguns momentos mais severos e em outros menos restritivos. O momento exige discussões sobre temas relacionados a interações pessoais e profissionais, saúde física e emocional, bem estar e situações de ansiedade.

O Projeto Transfere (Mediação de conhecimentos químicos entre universidade e comunidades)vem atuando em ações extensionistas desde 2012 e, juntamente com dois projetos parceiros, Projeto QuiCo (Estratégias de Ensino e Aprendizagem na Química do Cotidiano) ProjetoTICs (Tecnologias de Informação e Comunicação na Química)planejavam para o ano de 2020 o desenvolvimento de oficinas temáticas, estruturadas na metodologia dos Três Momentos Pedagógicos (3 MPs) (DELIZOICOV; ANGOTTI; PERNAMBUCO, 2002), em três escolas públicas da cidade de Pelotas-RSBrasil. Os Três Momentos Pedagógicos estão estruturados em Problematização Inicial no qual os alunos respondem questionamentos sobre o tema em questão a partir do que conhecem, a partir de suas vivências; Organização do Conhecimento momento no qual o professor aborda a explicação teórica do tema; Aplicação do Conhecimento momento que se destina a abordar sistematicamente o conhecimento incorporado pelo aluno.

Os três Projetos estão vinculados à Universidade Federal de Pelotas (UFPel) e ao Centro de Ciências Químicas, Farmacêuticas e de Alimentos (CCQFA), e realizavam, rotineiramente, oficinas temáticas em escolas públicas da cidade de Pelotas-RS. Além disso, divulgavam e disponibilizavam toda a produção didática, por meio de veículos digitais como o site do Projeto Transfere (https://projetotransfere.wixsite.com/projetotransfere) suas páginas @projetotransfereno Facebook e no Instagram. No entanto, o ano de 2020 foi um ano atípico, realmente sem precedentes na história recente mundial, que impossibilitou a interação presencial, típica e característica de ações extensionistas. Os estudantes, professores e comunidades escolares em geral, da rede pública, não realizaram ações presenciais no ano letivo 2020. Como consequência, nossa equipe não pôde atuar nas ações extensionistas previstas. Em face desta dificuldade e levando em consideração a formação e capacidade dos integrantes da equipe, graduandos da UFPel, em atuarem de maneira remota, o foco das ações extensionistas em 2020 foi direcionado à interação com as comunidades online por meio das redes sociais. Essa relação entre os Projetos e os ambientes virtuais já havia motivado, anteriormente, a divulgação articulada das ações de extensão universitária realizadas, bem como dos materiais didáticos produzidos (MOREIRA et al., 

(b)) sempre com o intuito de atingir o maior número possível de pessoas, disseminando conhecimentos e proporcionando meios de interação com o público por meio das mídias eletrônicas

Deste modo, para o projeto de extensão, a suspensão de atividades em campo não significou a quebra de vínculos com os parceiros do projeto, que obviamente estão fora da universidade, pelo contrário, se buscou novas maneiras de manter o vínculo, e a internet surgiu como uma ferramenta extensionista, Silverstone (2002) fala que "Não podemos escapar à mídia. Ela está presente em todos os aspectos de nossa vida", esta fala se fortifica principalmente nos dias de hoje, onde a internet colabora para manutenção de contato entre as pessoas.

Em face da situação, as ações no ano de 2020 foram concentradas na elaboração e divulgação de informações e instruções, por meio de panfletos digitais, de ações e medidas relacionadas à vivência da pandemia no cotidiano. Este material foi produzido através de um curso desenvolvido na plataforma Ava/Moodle da UFPel, pela coordenadora do Projeto, aos graduandos participantes dos projetos, visando a produção de material didático e de qualidade como resultado de ações de pesquisa, bem como sua divulgação nas mídias eletrônicas para alcançar o maior número de pessoas possível.

relação entre tecnologias e comunidades se apresenta cada vez mais próxima. A Tecnologia de Informação e Comunicação (TIC) contribui para essa relação e constituem um conjunto de recursos tecnológicos que podem proporcionar comunicação e/ou automação de diversos tipos de processos, em diversas áreas, inclusive na área de Educação em Química (FIORI; GOI, 2020). Essa tecnologia pode ser usada para compor, disponibilizar e compartilhar as informações por meio eletrônico (PEIXOTO; ARAÚJO, 2012). Godoi et al. (2019), afirmam que a TIC remodelou o sistema social entre jovens e crianças, devido ao cenário interativo, rápido e inovador que propiciam. Já os adultos, pais e professores, vivenciam momento diferente, pois conviveram com recursos tecnológicos diferentes durante sua fase de criança e adolescente. No entanto, independente da idade é impossível negar a influência e presença constante de tecnologias digitais na rotina das pessoas.

Assim, apresenta-se como objetivo deste artigo a descrição da realização de extensão universitária utilizando as redes sociais Facebook e Instagram para divulgar materiais didáticos informativos produzidos no ambiente universitário, com vistas a contribuir na educação e diminuição da disseminação do novo coronavírus e da doença COVID-19.

\section{REFERENCIAL TEÓRICO}

Segundo Lamarca et al. (2015), a TIC tem potencial para integrar um encaminhamento importante no objetivo de sustentar-se em debates e necessidades da sociedade, quando incorporadas à extensão universitária, isto é, com ênfase ao público não-acadêmico. (BRASIL, 2018). Assim, o compartilhamento de conhecimentos e informações proporcionadas pela TIC direciona a uma aprendizagem coletiva, onde a extensão universitária torna-se fundamental no processo de transmissão de informações. Considerando-se a complexidade do cenário social vigente, o 


\section{Revista Thema}

v.20

Especial 2021
:̊̊:

Edição Especial COVID-19

aprendizado cidadão que a extensão universitária proporciona aos graduandos, associado à carência das comunidades por informações de qualidade nas mídias sociais frente à quantidade de Fake News servem como incentivo à produção de materiais didáticos para as mídias digitais, com foco em inclusão de conteúdo digital. Para Silva et al. (2005), a inclusão digital é um processo que consiste em levar o indivíduo à aprendizagem no uso das tecnologias e ao acesso à informação disponível nas redes, especialmente àquela que traz um referencial para sua vivência diária e à comunidade na qual está inserido.

$\mathrm{Na}$ área da Educação, mudanças e propostas de ensino fazendo uso de TIC são constantemente referenciadas na literatura, sendo contínuas as pesquisas e as práticas que buscam contemplar melhorias na qualidade do processo de ensino e de aprendizagem de Ciências e de Química. (FIORI; GOI, 2020; NARDI, 2007; SANTOS; MALDANER, 2010), áreas nas quais o Projeto Transfere seus parceiros desenvolvem ações presenciais nas comunidades escolares, em períodos de normalidade. No entanto destaca-se, para o momento atual de isolamento social, a necessidade de estudo e reflexão sobre formas extensionistas não presenciais, fazendo com que conteúdos produzidos no meio acadêmico continuem chegando às comunidades de maneira clara e didática. Segundo Cunha (2019, p.13), "o valor da extensão universitária está justamente na forma de sua ação e atuação, ao lidar e defrontar-se com a realidade em constante movimento e, nesse sentido, melhor aprendê-la como processo". Logo, a realidade para o ano de 2020 evidenciou a necessidade de prevenção da disseminação da doença COVID-19 por meio de isolamento social. Assim, as ações do ProjetoTransfere e seus parceiros voltaram-se a comunidades online por meio da divulgação de conteúdo informativo em posts nas redes sociais Facebook e Instagram, levando em consideração que na atualidade grande parte da população faz uso das redes sociais para manter-se atualizada.

Atualmente, fazendo uso dos smartphones, as pessoas podem ter acesso às informações em todos os cenários de seu convívio. Por este motivo, as redes sociais se destacam como maneira de disseminação de informações, de divulgação de trabalhos e ideias, de trabalho e comércio. Além disso, um dos motivos do Facebook e Instagram terem grande alcance e bilhões de usuários é o fato de serem ferramentas de fácil manuseio e alta interatividade e conectividade entre seus membros. (TEIXEIRA, 2012). Por estes motivos, os apps são amplamente utilizados na comunicação, inclusive para a educação, por constituírem uma maneira ou método de aprendizagem diferenciado.

A utilização de redes sociais para contemplar aspectos educacionais e fins sociais já se apresenta como objeto de estudo. Aydin (2012) em seu estudo apresenta uma revisão da literatura acerca do Facebook como ferramenta para o desenvolvimento educacional, além de apresentar uma série de variáveis como, quem são os usuários e quais as razões para seu uso. Já a relação entre o Facebook e o ambiente universitário é singular desde sua criação, uma vez que, a rede social foi desenvolvida por estudantes universitários em 2004.

As redes sociais sempre apresentam atualizações que estimulam a interação e a comunicação, assim ganham grande alcance, que se expande anualmente (SCHERER; FARIAS, 2018) e que pode ter aumentado ainda mais em face do isolamento social. Apesar dos diversos relatos e estudos apresentados sobre a utilização do Facebook e Instagram para contemplar os processos de ensino 


\section{Revista Thema}

v.20

Especial 2021

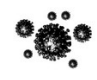

Edição Especial COVID-19

e aprendizagem envolvendo, tanto o ensino básico quanto o superior, há ainda carência de estudos em determinadas áreas e ações nas quais as redes sociais podem ser utilizadas, a exemplo da ausência de relatos de sua utilização para contemplar ações extensionistas. Este ponto pode ter relação com a essência das relações extensionistas de contato pessoa a pessoa. No entanto, num momento de adversidades, onde as relações presenciais foram brutalmente abaladas, uma alternativa é dar seguimento às ações extensionistas fazendo uso das redes sociais como promotoras de extensão universitária, como no caso das ações realizadas e descritas neste artigo.

Para tanto, conhecer novas metodologias de trabalho também implica em reconhecer dentro destas metodologias àquelas com as quais se obterá maior retorno e melhor desempenho. No âmbito acadêmico, o maior desafio no atual momento não está em produzir materiais, mas em fazer com que consigam contemplar o maior número possível de pessoas, atendendo aos requisitos de extensão universitária. Nesse contexto, acompanhar as tecnologias e conhecer meios e espaços de aprendizagem é extremamente relevante, a exemplo dos ambientes virtuais, como no caso das redes sociais. (ALMEIDA; VALENTE, 2014).

\section{METODOLOGIA}

As ações extensionistas do ProjetoTransfere sempre fizeram uso de recursos eletrônicos na divulgação de seus resultados e dos materiais didáticos produzidos, no entanto nunca como único meio de interação com o público alvo, como ocorreu no ano de 2020. Logo, as ações do Projeto e seus parceiros foram adaptadas para atender a atual demanda, fazendo uma mediação entre TIC, redes sociais e disseminação de informações confiáveis e úteis ao cotidiano das comunidades. Desta maneira, a vinculação do espaço universitário com a comunidade pode ser efetivo, como já indicado pela literatura (PORTO; SANTOS, 2014), que relata a potencialidade do Facebook em ambientes universitários para a propagação de conhecimentos.

A equipe dos Projetos é composta de estudantes de graduação dos cursos de Química Licenciatura, Química Bacharelado e Cinema e Animação e pela professora coordenadora dos Projetos e da atividade realizada no Ava/Moodle. Por meio dessa atividade, cada estudante confeccionou seu panfleto, com tema a escolha dentro da temática COVID-19 e suas implicações. Os estudantes de graduação estavam comprometidos com o conteúdo e com a estética do seu panfleto, sem sobrecarregá-los visualmente, de modo com que tornassem os posts atrativos para os leitores.

Desta maneira, houve a intenção de manifestar as ações extensionistas, mesmo estando distante fisicamente das comunidades. Os doze panfletos produzidos foram postados nas redes sociais Facebook e Instagram entre abril e agosto de 2020, com publicações de no mínimo uma vez por semana e no máximo duas. Ao passo que a cada novo material era postado nas redes sociais, era também divulgado no site, dessa forma, uma página ajudaria na divulgação da outra.

A análise dos dados após as publicações visou a investigação de um evento real, nesse caso as postagens de panfletos, levando em consideração seu contexto e ainda, buscando explicar 


\section{Revista Thema}

v.20

Especial 2021

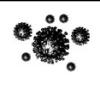

Edição Especial COVID-19

determinadas situações, para a causa deste evento. (GIL, 2008; YIN, 2005). O corpus de análise foi constituído pelos panfletos informativos.

De modo a contemplar uma análise mais detalhada de cada publicação no Facebook e Instagram e para fomentar as ações extensionistas por meio das redes sociais, foram considerados os resultados obtidos pela opção "engajamento", fornecida pelas plataformas e disponibilizada para os gerenciadores. Essa opção leva em consideração o "curtir", "comentar" e "compartilhar", ou seja, a interação do público com a publicação ou com a página. Além do "engajamento", também foi avaliado o "alcance orgânico", que a rede social apresenta como o número total de pessoas que visualizaram a publicação, através da distribuição gratuita. Os engajamentos bem como os alcances orgânico de cada postagem foram obtidos no dia 15 de agosto de 2020, após a publicação de todos os panfletos nas duas redes sociais. Deve-se ressaltar que a criação da página no Facebook data de 9 de junho de 2016, já a do Instagram é bem mais recente, com início em 25 de junho de 2020, o que reflete diretamente no número de seguidores que cada página possui e com o número de interações com as postagens. Quadro 1 apresenta o título de cada postagem feita nas redes sociais, bem como os links de acesso a essas publicações.

Quadro 1 - Publicações e seus links para acesso no Facebook e Instagram, respectivamente.

\begin{tabular}{|c|c|}
\hline Publicações & Links \\
\hline COVID-19 & $\begin{array}{l}\text { https://bit.ly/3fchiEI } \\
\text { https://www.instagram.com/p/CDmZOuXJtiO/? } \\
\text { utm source=ig web copy link }\end{array}$ \\
\hline $\begin{array}{l}\text { Não leve o coronavírus para dentro de casa: higienize roupas } \\
\text { e sapatos }\end{array}$ & $\begin{array}{l}\text { https://bit.ly/30fjpmP } \\
\text { https://www.instagram.com/p/CCwZKgJBxh2/ }\end{array}$ \\
\hline A importância do uso de máscaras & $\begin{array}{l}\text { https://bit.ly/3k1x5cY } \\
\text { https://www.instagram.com/p/CCMXgLqhowg/ }\end{array}$ \\
\hline $\begin{array}{l}\text { Diminua os riscos de contaminação com a COVID-19: fique } \\
\text { em casa }\end{array}$ & $\begin{array}{l}\text { https://bit.ly/3hVSm6k } \\
\text { https://www.instagram.com/p/CDKLUKHBVdp/ }\end{array}$ \\
\hline Quando procurar ajuda médica para tratar a COVID-19? & $\begin{array}{l}\text { https://bit.ly/3jYiPBM } \\
\text { https://www.instagram.com/p/CCehJuGBNjj/? } \\
\text { utm source=ig web copy link }\end{array}$ \\
\hline Fake News e o novo coronavírus & $\begin{array}{l}\text { https://bit.ly/30g355g } \\
\text { https://www.instagram.com/p/CDcU63HBRVE/ }\end{array}$ \\
\hline $\begin{array}{l}\text { Medidas de distanciamento social contra o coronavírus: } \\
\text { ampliado, seletivo e lockdown }\end{array}$ & $\begin{array}{l}\text { https://bit.ly/2Xfybbm } \\
\text { https://www.instagram.com/p/CDCc12PBcf9/ }\end{array}$ \\
\hline Como manter a rotina de estudo durante a pandemia & $\begin{array}{l}\text { https://bit.ly/3fgUbJ6 } \\
\text { https://www.instagram.com/p/CDUeZpABIQR/ }\end{array}$ \\
\hline Ações de prevenção nos serviços essenciais e não essenciais & $\begin{array}{l}\text { https://bit.ly/3hVfZvM } \\
\text { https://www.instagram.com/p/CCCErEKBTQH/ }\end{array}$ \\
\hline Como cuidar da saúde mental durante a pandemia? & $\begin{array}{l}\text { https://bit.ly/3jSpsFM } \\
\text { https://www.instagram.com/p/CCUI3reB3vT/ }\end{array}$ \\
\hline
\end{tabular}


Fonte: Elaborado pelos autores.

\section{RESULTADOS E DISCUSSÕES}

Os doze panfletos produzidos e publicados foram codificados com letras do alfabeto (A-L) (Quadro 1), em ordem cronológica de publicação no Facebook,sendo que um destes panfletos é apresentado na Figura 1.

Figura 1 - Panfleto "J" publicado nas redes sociais.

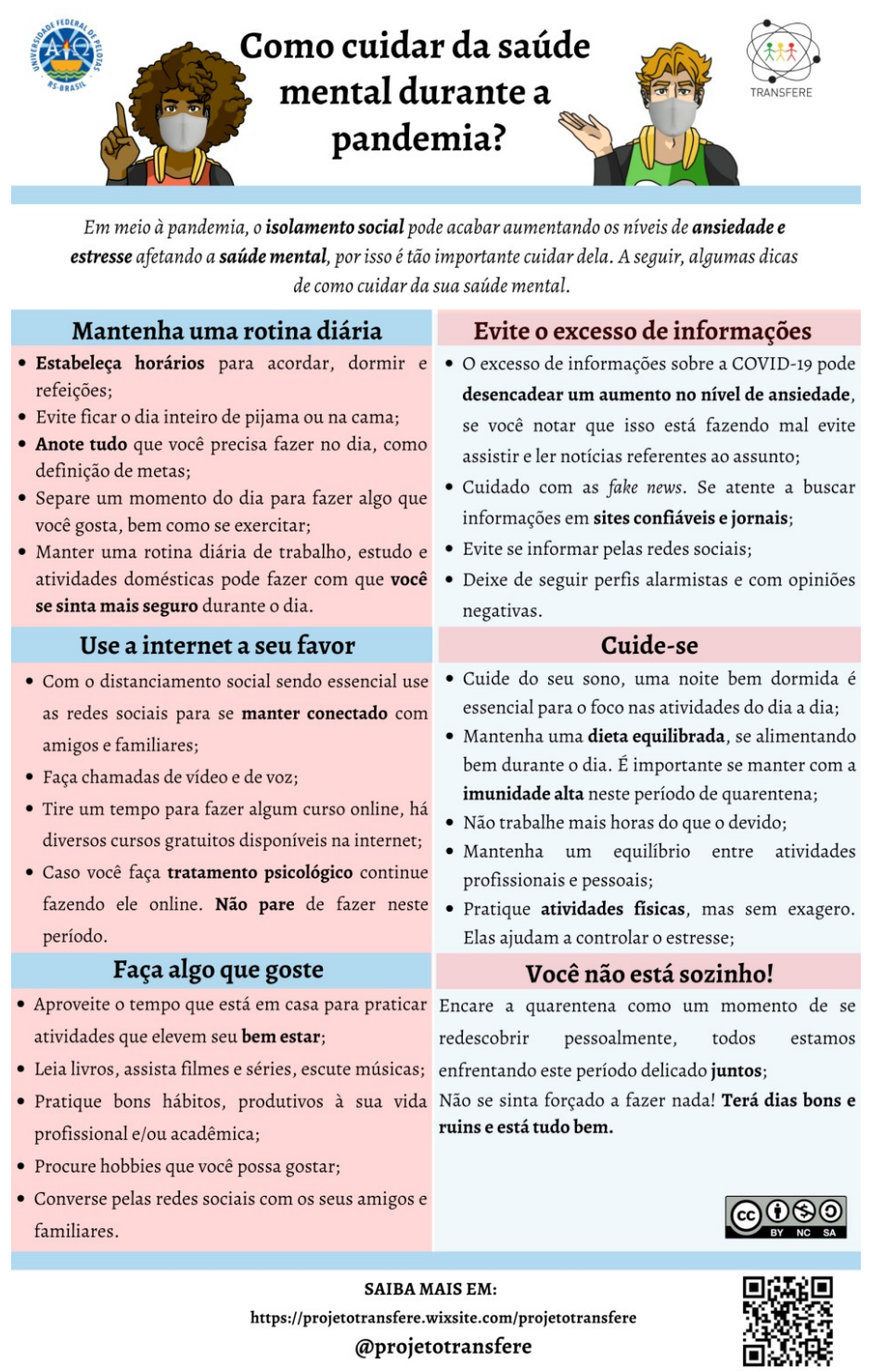

Fonte: Adaptado de Moreira et al. (2020(a)(b)). 
Os demais panfletos podem ser conferidos diretamente nas redes sociais segundo informações e links de acesso contidos no Quadro 1. Vale ressaltar que as publicações no Instagram possuem uma ordem diferente, pois o perfil nessa rede social foi criado somente após o início da divulgação dos posts no Facebook. A criação do perfil no Instagram mostrou-se como uma demanda por ser uma rede social cujo público é formado, principalmente, por jovens. Deve-se ressaltar que cada estudante de graduação membro da equipe, seja voluntário ou bolsista, escolheu o layout de seu panfleto, assim todos os panfletos são diferentes entre si.

A primeira publicação no Facebook ocorreu no dia 15 de abril e a última no dia 20 de julho. No Instagram, a primeira publicação ocorreu no dia 29 de junho e a última no dia 7 de agosto. Os doze panfletos também foram publicados no site do Projeto Transfere.

Os dados apresentados no Quadro 2 referem-se à data de 15 de agosto de 2020 e mostram diferença nos "engajamentos" e de "alcance orgânico" ao comparar as duas redes sociais. Essa diferença é reflexo do número de seguidores e do tempo de existência de cada página. A página do Facebook conta com 392 seguidores e foi criada em 2016, enquanto que a página no Instagram conta com um total de 77 seguidores e foi criada em 2020.

Quadro 2 - Interações obtidas com as publicações no Facebook/Instagram.

\begin{tabular}{|l|l|l|l|l|}
\hline Publicações & Engajamentos & Alcances Orgânicos & Curtidas & Compartilhamentos \\
\hline & $99 / 7$ & $1.967 / 64$ & $14 / 7$ & $17 / 0$ \\
\hline & $129 / 9$ & $2.474 / 71$ & $9 / 9$ & $28 / 3$ \\
\hline & $99 / 12$ & $2.158 / 82$ & $11 / 12$ & $24 / 2$ \\
\hline & $86 / 11$ & $1.801 / 64$ & $17 / 11$ & $24 / 4$ \\
\hline & $64 / 15$ & $1.693 / 88$ & $7 / 14$ & $16 / 4$ \\
\hline & $78 / 10$ & $2.753 / 80$ & $4 / 10$ & $19 / 1$ \\
\hline & $89 / 14$ & $2.155 / 83$ & $5 / 13$ & $21 / 3$ \\
\hline & $255 / 10$ & $5.527 / 82$ & $13 / 9$ & $24 / 2$ \\
\hline & $44 / 16$ & $1.474 / 66$ & $7 / 16$ & $13 / 0$ \\
\hline & $232 / 21$ & $5.511 / 108$ & $10 / 18$ & $27 / 4$ \\
\hline & $85 / 18$ & $2.719 / 72$ & $7 / 18$ & $22 / 1$ \\
\hline Total & $122 / 11$ & $2.946 / 73$ & $5 / 11$ & $19 / 2$ \\
\hline & $1.382 / 154$ & $33.178 / 933$ & $109 / 148$ & $254 / 26$ \\
\hline
\end{tabular}

Fonte: Elaborado pelos autores.

Os panfletos alcançaram um número considerável de pessoas nas comunidades online, mesmo que o número de curtidas e compartilhamentos não tenha sido expressivo. Conforme foram sendo feitas as publicações foi possível notar um crescimento em relação ao número de curtidas nas páginas, sendo eu cada interação a mais é um indício de disseminação de informações. Em relação ao alcance orgânico, evidenciou-se que o número de pessoas contempladas com as publicações é superior ao número de seguidores nas páginas, ou seja, não foram apenas os seguidores que 


\section{Revista Thema}

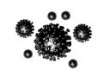

\begin{tabular}{l|l|l} 
v.20 & Especial & 2021
\end{tabular}

\section{Edição Especial COVID-19}

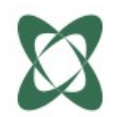

visualizaram os materiais produzidos, isto é, o alcance das publicações supera o número de seguidores. Assim, e monitoramento levou em consideração tanto o público que segue a página quanto aqueles que não seguem, mas que visualizaram a publicação por meio de uma curtida, um comentário ou compartilhamento de um amigo.

Os valores totais de alcances orgânicos com as doze publicações foram 33.178 no Facebook e 933 no Instagram, respectivamente. relação de alcance orgânico com os resultados de engajamento em cada uma das publicações em ambas as redes sociais, é ilustrada nas Figuras 2 e 3. A Figura 4 mostra a comparação de alcance orgânico obtido no Facebook e Instagram.

Figura 2 - Engajamento e alcance orgânico de cada panfleto no Facebook.

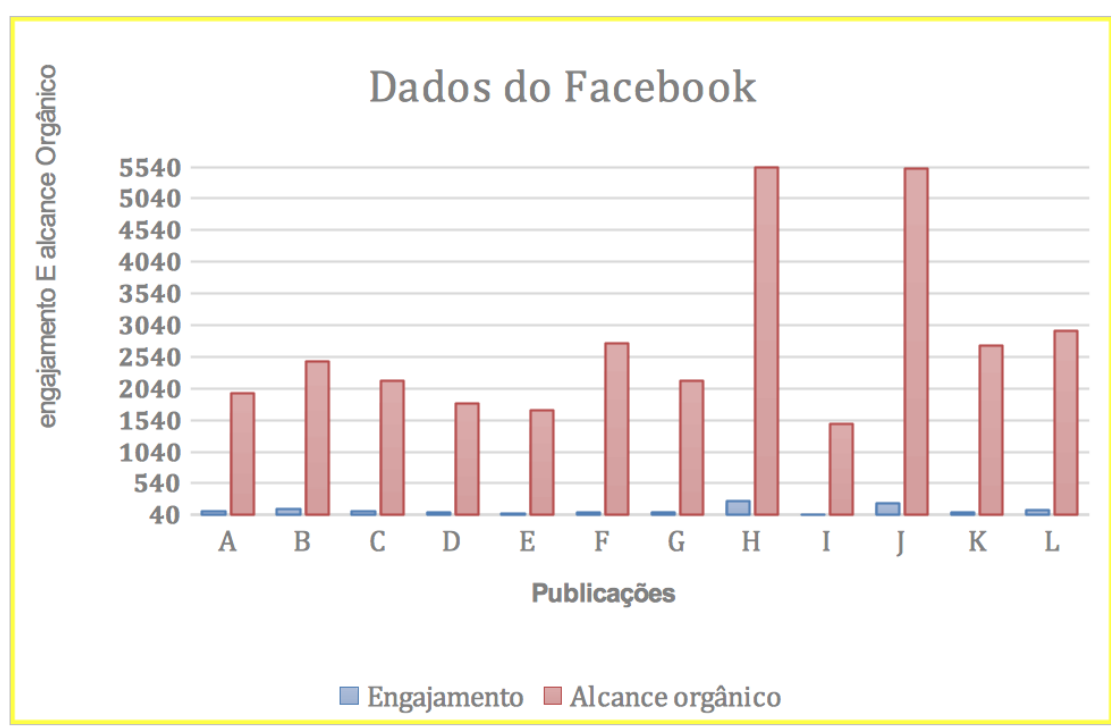

Fonte: Elaborada pelos autores.

Figura 3 - Engajamento e alcance orgânico de cada panfleto no Instagram.

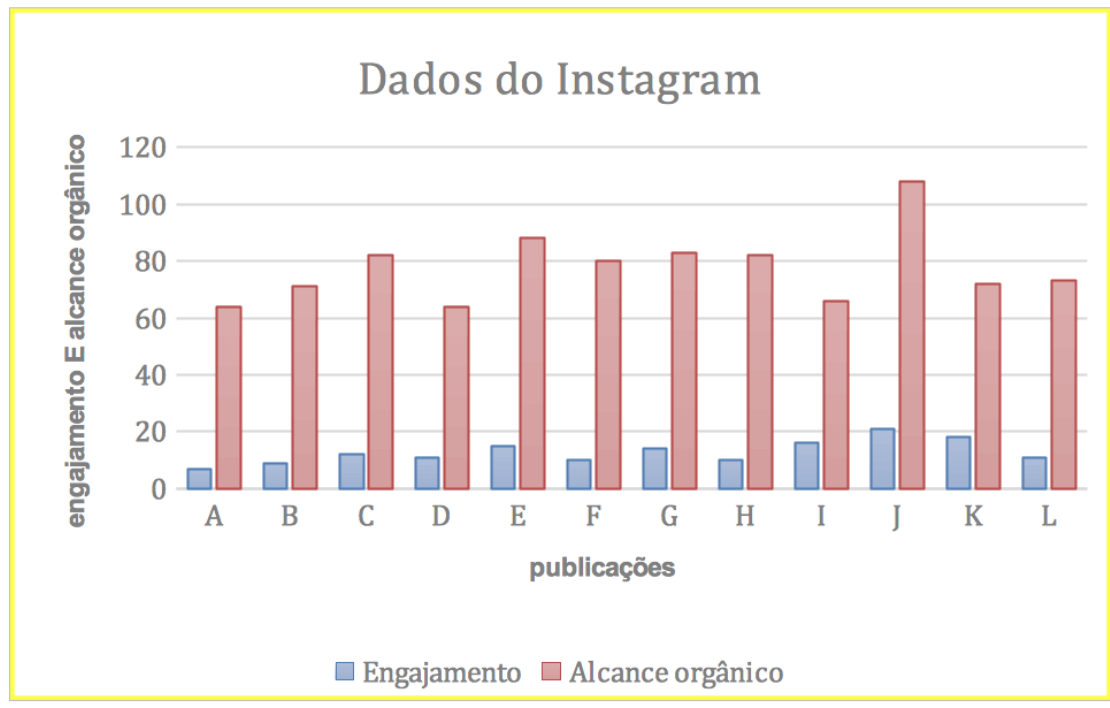

Fonte: Elaborada pelos autores. 
Figura 4 - Alcance orgânico dos panfletos no Facebook e Instagram.

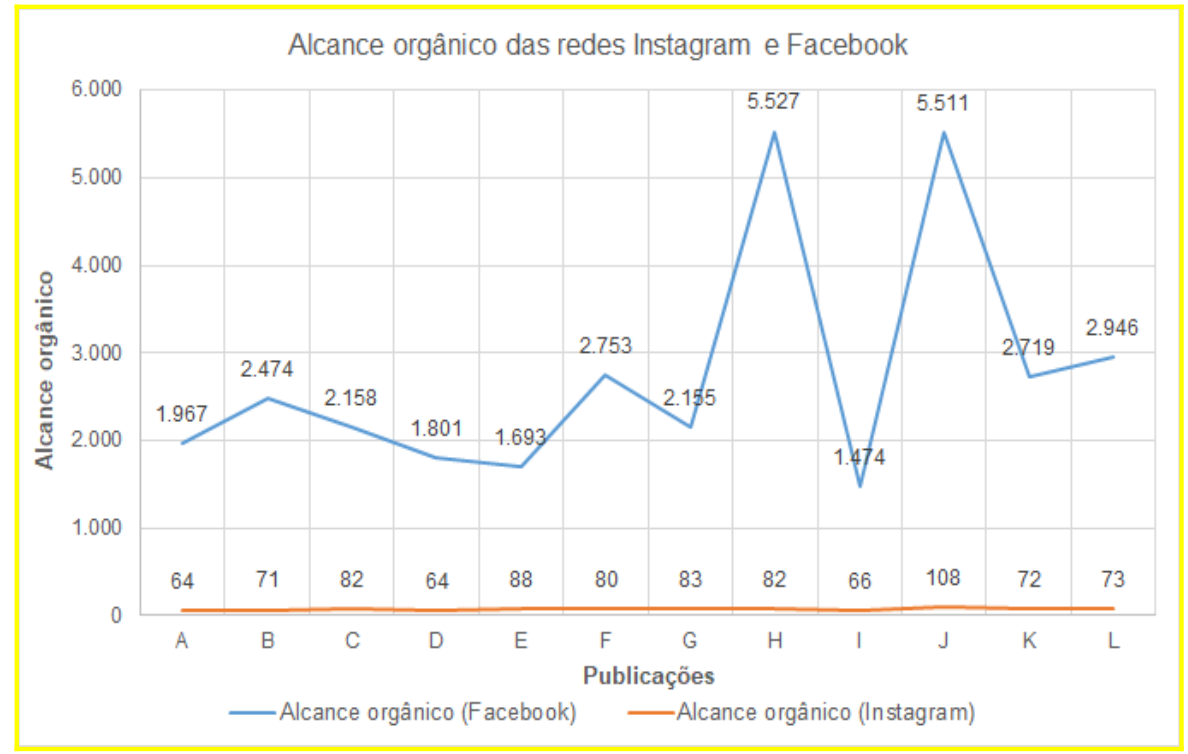

Fonte: Elaborada pelos autores.

A relação entre os alcances orgânicos e os engajamentos é estreita, isto é, maiores alcances orgânicos mostram maiores engajamentos e vice-versa. Os panfletos que mais se destacaram no Facebook tiveram alcance de 5.527 pessoas e 255 engajamentos para " $\mathrm{H}$ ", e alcance de 5.511 pessoas e 232 engajamentos para "J". Essa relação entre o alcance orgânico e o engajamento, ou seja, entre o número de pessoas alcançadas e de engajamentos que as pessoas tiveram com 0 panfleto, também é notado nas publicações com número de acessos menos expressivos.

Os panfletos que tiveram os maiores alcances orgânicos " $\mathrm{H}$ " e "J" podem ter contemplado um maior número de pessoas pelo fato de terem sido publicados na semana em que o assunto se mostrava mais relevante. O panfleto "H - Como manter a rotina de estudo durante a pandemia" foi publicado no Facebook na semana de início das aulas do calendário alternativo e remoto da Universidade, mais precisamente no dia 22 de junho. Já o panfleto "J - Como cuidar da saúde mental durante a pandemia?", por tratar de um assunto mais delicado, relacionado diretamente a hábitos que podem ajudar durante o período de isolamento social, pode ter chamado a atenção, uma vez que nesse período, foram necessárias muitas mudanças nos hábitos e adaptações, sendo que algumas dessas mudanças mostraram-se de grande importância para manter os cuidados com a saúde física e mental durante a pandemia. Além disso, é fato que grande parte das pessoas encontrou, em algum momento, dificuldades em manter sua rotina, seja ela de estudos ou de trabalho. Essa dificuldade em acertar a rotina durante o isolamento social pode vir a prejudicar a saúde mental das pessoas. Neste sentido, ambas as publicações " $\mathrm{H}$ " e "J" apresentaram sugestões de como lidar com situações mantendo o bem-estar e a rotina produtiva, sendo que esses pontos podem ter contribuído para o seu maior alcance orgânico.

Já para os panfletos que mostraram menor alcance orgânico, " $A$ ", "D" e "I", concluímos que tratam-se de temas que não eram de interesse do público, possivelmente por não serem considerados relevante, por já serem conhecidos ou, ainda, por não mostrarem relação com a 
realidade das comunidades online Por exemplo, o panfleto "A- COVID-19" foi o último a ser publicado no Instagram, mesmo contendo informações atualizadas, ainda assim se tratava de explicar o conceito de vírus, como prevenir a doença, entre outras informações que já vinham sendo retratadas pela mídia. Por este motivo, o panfleto " $A$ " pode não ter repercutido tanto quanto outros panfletos. O mesmo pode ter ocorrido com o panfleto " - Diminua os riscos de contaminação com a COVID-19: fique em casa". Já o panfleto "I - Ações de prevenção nos serviços essenciais e não essenciais" pode não ter chamado a atenção do público e evidenciado o desinteresse em saber quais serviços estariam funcionando normalmente durante 0 isolamento social e quais não estariam, ou que medidas seriam adotadas em cada estabelecimento, sendo que o ideal seria todos permanecer ao máximo em suas casas.

A partir desse estudo que analisou ações extensionistas mediadas pela TIC nas redes sociais e considerando a interação das comunidade online com os doze posts, destaca-se uma perspectiva de aumento da interação entre pessoas por meio das mídias sociais, bem como de pessoas com conteúdos interativos, frente ao prolongamento do isolamento social. Nosso intuito com as futuras postagens sobre temas de Ciências e Química com foco para jovens, é alcançar um número ainda maior de pessoas, já que a partir deste ano as redes sociais consolidam-se como meio de interação virtual em substituição à interação presencial.

Como experiência destes panfletos postados, trazemos que o ideal seriam posts mais concisos, com figuras interessantes e apenas uma ou duas frases de texto, quiz, memes, curiosidades etc., para atender ao padrão jovem das redes sociais, principalmente do Instagram, o que está sendo considerado para as próximas postagens.

Com a realização das ações extensionistas de divulgação dos panfletos digitais, bem como sua confecção pelos integrantes dos Projetos, foi notável a apropriação de ferramentas digitais necessárias à produção dos conteúdos, além da capacitação por meio da pesquisa por informações confiáveis acerca da COVID-19.

\section{CONSIDERAÇÕES FINAIS}

Fazer das mídias digitais o único meio de interação comas comunidades, como forma de exercer extensão universitária, tem sido algo novo e desafiador para o ano de 2020. Os panfletos criados e divulgados nas redes sociais Facebook e Instagram sobre o tema COVID-19 e suas implicações visavam educação, qualidade de vida e instrução ao público em geral, por isso a avaliação da quantidade de pessoas alcançadas e/ou assistidas foi um dado importante. A partir disso, evidenciou-se o potencial extensionista de informações de qualidade produzidas no âmbito acadêmico e divulgadas nas redes sociais. Com o avanço das tecnologias e a facilidade de se criar materiais para as mídias sociais, bem como a comodidade no alcance das comunidades, é cada vez mais importante utilizar esses meios para a divulgação de informações relevantes.

Grande parte da população faz uso de plataformas digitais, principalmente o público jovem com idade escolar para ensino médio, que anteriormente à pandemia era o principal público alvo das ações do Projeto Transfere e seus colaboradores, que ocorriam presencialmente em escolas públicas. No entanto, os acontecimentos neste ano de 2020 comprovaram que formas de produzir 
e transmitir informações científicas são constantemente atualizadas, sendo que novas tecnologias proporcionam novos modos de produção, registro e armazenamento. Conforme apresentado nesse estudo, foi possível disseminar informações às comunidades online por meio das redes sociais e receber respostas de "alcance orgânico" às ações de extensão universitária promovidas, tendo um grande alcance geral de cerca de 30 mil pessoas.

As ações futuras de nossa equipe preveem a volta de ações extensionistas típicas de contato e interação entre pessoas, assim que for possível, acrescido de uma campanha de divulgação de conteúdos de Ciências e Química nas redes sociais, com intuito de aumentar o número de seguidores nas páginas do Projeto Transfere e disseminar na web, para o público jovem, materiais didáticos e de qualidade produzidos no âmbito acadêmico. Além disso, também como experiência desta atividade para futuras postagens, uma padronização no layout dos panfletos será realizada de maneira a facilitar a identificação visual das publicações do grupo nas redes sociais, bem como a produção de posts que atendam padrões mais visuais e com menos texto, de acordo com o que vem sendo considerado como mais atrativo nas mídias virtuais.

\section{AGRADECIMENTOS}

Pró-Reitoria de Extensão e Cultura (PREC) e Pró-Reitoria de Ensino (PRE) da Universidade Federal de Pelotas (UFPel).

\section{REFERÊNCIAS}

ALMEIDA, M. E. B. de; VALENTE, J. A. Currículo e contextos de aprendizagem: integração entre o formal é o não-formal por meio de tecnologias digitais. E-curriculum, São Paulo, v.2, n.12, p.1162-1188, 2014.

AYDIN, S. A review of research on Facebook as an educational environment. Educational Technology Research and Development, n.60, p.1093-1106, 2012.

BRASIL. Resolução $\mathbf{n}^{\mathbf{0}} \mathbf{7}$ de $\mathbf{1 8}$ de dezembro de 2018. Estabelece as Diretrizes para a Extensão na Educação Superior Brasileira e regimenta o disposto na Meta 12.7 da Lei no 13.005/2014 que aprova o Plano Nacional de Educação - PNE 2014-2024 e dá outras providências. Disponivel em: https://bit.ly/3hP8In5. Acesso em: 01 jul. 2020.

CUNHA, E. J. L. O desenvolvimento das ações de extensão em educação a distância nas universidades públicas brasileiras. In: CORRADI, W. et al. (Org.). Extensão Universitária na EAD. Belo Horizonte: UFMG, 2019. p.11-15.

DELIZOICOV, D.; ANGOTTI, J. A. P.; PERNAMBUCO, M. M. Ensino de ciências: fundamentos e Métodos. São Paulo: Cortez, 2002. p.617-638.

FIORI, R.; GOI, M. E. J. O Ensino de Química na plataforma digital em tempos de Coronavírus.

Revista Thema, v.18, n.especial, p.218-242, 2020.

GIL, A. C.; Métodos e técnicas de pesquisa social. 6. ed. São Paulo: Atlas, 2008. 
GODOI, M. V. M. et al.Representações sociais e uso de tecnologias educativas na escola. Revista Intersaberes, v.13, n.29, p.342-353, 2019.

LAMARCA, D. S. F. et al. Tecnologia e sociedade: a inclusão digital das TIC no projeto de extensão universidade aberta à terceira idade (UNATI). Revista da Pró-Reitoria de Extensão e Cultura Raízes e Rumos, Rio de Janeiro, v.3, n.2, p.82-89, 2015.

MOREIRA, L. $L$ et al. $O$ uso das redes sociais na extensão universitária em tempos de pandemia. In: SEMINÁRIO DE EXTENSÃO UNIVERSITÁRIA DA REGIÃO SUL, 38., 2020. Londrina. Anais... Londrina: UEL, 2020(a).

MOREIRA, L. L. et al. Relação entre extensão universitária e redes sociais. In: CONGRESSO DE EXTENSÃO E CULTURA, 6., 2020, Pelotas. Anais... Pelotas: UFPel, 2020(b).

NARDI, R. A pesquisa em Ensino de Ciência/s no Brasil: alguns recortes. São Paulo: Escrituras, 2007.

PEIXOTO, J.; ARAUJO, C. H. S. Tecnologia e educação: algumas considerações sobre o discurso pedagógico contemporâneo. Educação e Sociedade, v.33, n.118, p.253-268, Campinas, 2012.

PORTO, C.; SANTOS, E. Facebook e educação: publicar, curtir, compartilhar. Campina Grande: EDUEPB, 2014. p.15-23.

PROJETO TRANSFERE. 2020. Disponível em: https://projetotransfere.wixsite.com/projetotransfere. Acesso em: 27 nov. 2020.

SANTOS, A. J. R. W. A. et al. Diálogos, mediação de experiências e aprendizados em comunidades escolares. Expressa Extensão, v.25, n.3, p.20-31, 2020(a).

SANTOS, A. J. R. W. A. et al. Mediação de Conhecimentos de Química associados ao cotidiano através das ações de extensão do Projeto Transfere. In: MICHELON, F. F.; BANDEIRA, A. da R. A Extensão Universitária nos 50 Anos da Universidade Federal de Pelotas. Pelotas: Universidade Federal de Pelotas, 2020(b). p.781-795.

SANTOS, A. J. R. W. A.; LAMPE, L.; SANGIOGO, F. A. O aprimoramento de conhecimentos populares por meio de oficina temática envolvendo a química do cotidiano. Expressa Extensão, v.24, n.1, p.141-152, 2019.

SANTOS, W. L. dos.; MALDANER, O. A. Ensino de Química em Foco. Ijuí: Unijuí, 2010.

SCHERER, A. L.; FARIAS, J. G. Uso da Rede Social Facebook como Ferramenta de Ensinoaprendizagem em Cursos de Ensino Superior. Revista Brasileira de Aprendizagem Aberta e a Distância, v.17, n.1, p.1-20, 2018.

SILVA, H. et al. Inclusão digital e educação para a competência informacional: uma questão de ética e cidadania. Ciência da Informação, v.34, n.1, p.28-36, 2005.

SILVA, V. S. et al. A utilização de TICs no estudo de temas de Química do cotidiano. In: ENCONTRO DE DEBATES SOBRE ENSINO DE QUÍMICA, 38., 2018, Canoas. Anais... Canoas: Ulbra, 2018(a). 


\section{:a:}

v.20

\begin{tabular}{l|l} 
Especial & 2021
\end{tabular}

\section{Edição Especial COVID-19}

SILVERSTONE, R. Por que estudar a mídia? 2. ed. São Paulo: Edições Loyola, 2002.

TEIXEIRA, M. A. P. O Facebook e os estudantes universitários: Função, Interacções e Contributos da Rede Social. 2012. 164 f. Dissertação (Mestrado em Psicologia) - Universidade de Évora, Évora, Portugal, 2012.

YIN, R. K. Estudo de caso: planejamento e métodos. 3. ed. Porto Alegre: Bookman, 2005. 